INVESTIGACIÓN

Recibido: 16/03/2021 --- Aceptado: 16/03/2021 --- Publicado: 24/05/2021

\title{
ANÁLISIS LEXICOMÉTRICO DE LOS MENSAJES PUBLICITARIOS DE LAS GRANDES MARCAS EN ESPAÑA ANTE LA CRISIS DEL COVID
}

\section{Lexicometric analysis of the advertising messages of the big brands in Spain in the face of an unpublished crisis}

Raquel Sánchez Sandoval. ${ }^{1}$ Universidad de Valladolid. España. raquel.sanchez.sandoval@uva.es

\section{Cómo citar el artículo:}

Sánchez Sandoval, R. (2021). Análisis lexicométrico de los mensajes publicitarios de las grandes marcas en España ante la crisis del COVID. Vivat Academia. Revista de Comunicación, 154, 185-212. http://doi.org/10.15178/va.2021.154.e1343

http://www.vivatacademia.net/index.php/vivat/article/view/1343

\section{RESUMEN}

La crisis de la COVID-19 es una crisis sociosanitaria, política y económica, pero sobre todo es una crisis internacional y sin precedentes. Ante esta difícil situación, las grandes marcas se han visto obligadas a procurar cambios en todos los sentidos. Desde una perspectiva publicitaria, esta investigación se plantea para averiguar los cambios exactos que se hayan podido producir para adaptar sus mensajes publicitarios al nuevo escenario de pandemia. Mediante una metodología basada en el análisis de contenido, se lleva a cabo una revisión lexicométrica de los mensajes de cerca de una veintena de marcas muy relevantes para la economía española, y se comparan los copies utilizados por estas durante el año 2019 con los del 2020, a partir del momento en el que se decreta el estado de alarma. El objetivo es comprobar la existencia de una tendencia al cambio, que se intuye peculiar, por cuanto se parte de la hipótesis de que las estrategias comunicativas de las marcas objeto de estudio adoptan una doble finalidad: la social y la comercial, aunando a ambas en sus mensajes, para mostrar su empatía al público ante las nuevas circunstancias de crisis sobrevenidas, mientras sus mensajes siguen constituyendo un recuerdo fiel de su labor empresarial para el consumidor. La perseverancia de estas marcas ante la incertidumbre y la adversidad se ha traducido en mensajes muy variopintos que, una vez analizados, dan fe de su

\footnotetext{
1 Raquel Sánchez Sandoval. Profesora asociada de la Universidad de Valladolid, España.

Correo: Raquel.sanchez.sandoval@uva.es
} 
Análisis lexicométrico de los mensajes publicitarios de las grandes marcas en España ante la crisis del COVID

gran capacidad de cambio y adaptabilidad, apostando por la publicidad como valor seguro ante este inédito momento.

PALABRAS CLAVE: COVID - Mensajes - Publicidad - Comunicación - Pandemia Mercadotecnia - Lexicométrico.

\section{ABSTRACT}

The COVID-19 crisis is a social, political and economic crisis, but above all it is an international and unprecedented crisis. Faced with this difficult situation, the big brands have been forced to seek changes in all senses. From an advertising perspective, this research is proposed to find out the exact changes that may have occurred to adapt their advertising messages to the new pandemic scenario. Using a methodology based on content analysis, a lexicometric review of the messages of about twenty brands very relevant to the Spanish economy is carried out, and the copies used by these during 2019 are compared with those of 2020, from the moment in which the alarm state is decreed. The objective is to verify the existence of a tendency to change, which is perceived as peculiar, since it is based on the hypothesis that the communication strategies of the brands under study adopt a double purpose: social and commercial, combining both in his messages, to show his empathy to the public in the face of new circumstances of crisis, while his messages continue to be a faithful reminder of his business work for the consumer. The perseverance of these brands in the face of uncertainty and adversity has resulted in very diverse messages that, once analyzed, attest to their great capacity for change and adaptability, betting on advertising as a safe value in the face of this unprecedented moment.

KEYWORDS: COVID - Messages - Advertising - Comunication - Pandemic Marketing - Lexicometric

\section{INTRODUCCIÓN Y ESTADO DE LA CUESTIÓN}

Vivimos en un entorno altamente variable, sobre todo dependiente de un sistema económico cada vez más inestable por los acontecimientos de una serie de crisis que llevamos arrastrando hace años. En España, concretamente, tenemos el lastre aún no solucionado de una crisis económica de hace más de una década, acompañada de una irrefrenable corrupción política. A esto se han incorporado en 2020 otra crisis, sanitaria, provocada por una pandemia internacional que nos llevará sin duda a una etapa complicada y difícil de superar a corto plazo.

Esta pandemia fue provocada por un virus que, presuntamente, se originó en China a finales del año 2019. El 31 de enero de 2020 se conoció el primer caso de enfermedad de coronavirus en España. El virus se propaga por todo el mundo, incluida España, y es el 11 de marzo cuando la Organización Mundial de la Salud declara oficialmente el estado de pandemia. Tan solo 3 días más tarde, el 14 de marzo, el presidente de España, Pedro Sánchez, declara el estado de alarma que recoge el Real Decreto 463/2020, de 14 de marzo. Esta situación hizo que en marzo los españoles sufriéramos un

Vivat Academia. Revista de Comunicación. 2021, nº 154, 185-212 
confinamiento domiciliario, producido por los elevados casos de fallecimientos como consecuencia del virus SARS-CoV-2.

Partiendo de ese momento, dado que ha sido inédito, se plantea un seguimiento y estudio de la adaptación de los mensajes publicitarios de numerosas empresas y marcas líderes en nuestro mercado, a fin de comprobar, mediante una revisión lexicométrica, los cambios que se han podido producir en estos para acoplarlos a la situación de pandemia, indagando en las diferencias que en tal caso hayan tenido lugar respecto de sus campañas del año anterior, 2019.

En un ambiente cada vez más hostil para las empresas, tanto a nivel nacional como internacional, que ha obligado a muchas al cierre tras no poder resistir las cargas económicas derivadas de las duras restricciones, las más afortunadas, a pesar de las circunstancias, hacen demostración de poderío en su publicidad cuando incorporan frases como "todos juntos resistiremos". Esto significa que se están incluyendo en el mensaje como parte afectada del problema. Efectivamente, no debemos olvidar que de las crisis siempre surgen oportunidades, e incluso las marcas pueden verse beneficiadas elaborando mensajes de apoyo, de unidad, de supervivencia intentando mostrar su cara más solidaria o fortaleciendo su imagen corporativa:

La marca sólo hace referencia a la crisis económica en su publicidad cuando con ello va a conseguir que la vean como una marca fuerte, bien sea por su evolución o historia, bien sea porque su negocio se adapta mejor a un entorno de crisis. (Caride, 2019, p.157)

El mensaje publicitario, analizado desde el punto de vista lingüístico es, básicamente, el texto que elaboran las marcas para comunicar algo, y sirve para adaptarse a los objetivos que establece la empresa en determinados momentos. Dependiendo del contexto y de las imágenes que le acompañen puede tener multitud de funciones y de connotaciones. "Ambos componentes no se encuentran separados radicalmente, puesto que, aunque su naturaleza es heterogénea, aportan significados que son asimilados por el receptor en un mismo acto comunicativo." (Hernando, 1994, p. 514)

Hoy en día, la estrategia de marca evoluciona y se mueve a la misma velocidad del entorno, gracias también a las nuevas formas de comunicación online. La mejor manera de acercarse al consumidor es hablar con él, escucharle, conocerle, empatizar con él, en definitiva, saber cuales son sus necesidades en cada momento y adaptarse a las circunstancias como afirma Pol, "las marcas y las empresas se adaptan con flexibilidad y versatilidad al entorno cambiante. La marca es un sistema abierto frente a los cambios" (2015, p. 110). Esto no es nada nuevo, pero sí lo es esta situación experimental, "ilusoria" y novedosa que tiene que ver con la convivencia con una pandemia.

No hay que olvidar el compromiso moral, social que tienen las empresas con la sociedad y en momentos como estos es cuando deben aportar un valor añadido de ética, de responsabilidad que aporte ese plus de integridad tanto a su imagen 
corporativa como a los stakeholders. "La empresa concienciada mantiene informado de su compromiso a su público, pero también decide emprender nuevas acciones de comunicación/concienciación, donde el público al que van dirigidos sus mensajes es el público ciudadano, ya sea consumidor o no". (Mut y Bernad, 2011, p. 603)

En primer lugar, se ha planteado este estudio lexicométrico, porque puede ser interesante como punto de partida para otros de carácter más pragmático, y a fin de contribuir a desgranar aspectos significativos de la comunicación. Los análisis lexicométricos se han planteado como estudios metodológicos alternativos, se caracterizan por ser un "proceso secuencial donde el investigador reflexiona sobre los datos, los categoriza y los relaciona con el propósito de identificar las categorías centrales que aportan información emergente a la comprensión de un problema particular" (Barreto, Velandia-Morales, y Rincón-Vásquez, 2011, p. 12) y se han empleado para estudiar una gran variedad de sectores, como es el caso de Terrazas (2016) cuando lo aplica al estudio de las concepciones del aprendizaje , o Fernández y Fuentes (2000) cuando analizan el léxico del periódico El Socialista; o el análisis que hacen Vázquez, Mengual y Roig (2015) de la escritura digital de adolescentes en WhatsApp un sinfín de posibilidades para redefinir expresiones desde diferentes puntos de vista temáticos.

\section{OBJETIVOS DE INVESTIGACIÓN}

El objetivo principal de este estudio es, fundamentalmente, conocer si los anunciantes han cambiado su discurso publicitario adaptándose a la nueva situación de pandemia y de confinamiento, y comprobar si incluso esos cambios los han extendido a los meses posteriores en los que todavía dura la crisis sanitaria.

Como objetivo específico, se trataría de cuantificar cuales son los términos más usados dentro del corpus seleccionado en años 2019 y 2020, respectivamente, y como esos términos se correlacionan con el nuevo discurso en situación COVID.

\section{METODOLOGÍA}

\subsection{Muestra}

El corpus está compuesto por 30 spots publicitarios que representan a 15 de los 20 anunciantes que hicieron una mayor inversión publicitaria en España durante el año 2019 según el análisis anual de Infoadex (ver tabla 1). Se han seleccionado 2 spots como representación de cada anunciante, uno del año 2019 y otro del año 2020. Por lo que el corpus queda compuesto por 15 spots del 2019 y 15 del 2020. 
Sánchez Sandoval, R.

Análisis lexicométrico de los mensajes publicitarios de las grandes marcas en España ante la crisis del COVID

Tabla 1. Ranking de Anunciantes con mayor inversión en 2019 en España

\begin{tabular}{|l|l|c|c|}
\hline \multicolumn{2}{|l|}{ TOP 10 ANUNCIANTES 2019 EN INVERSIÓN CONTROLADA } & $\begin{array}{c}\text { INVERSIÓN 2019 } \\
\text { MILLONES } €\end{array}$ & $\begin{array}{c}\text { CUOTA SOBRE } \\
\text { TOTAL 2019 }\end{array}$ \\
\hline 1 & VOLKSWAGEN GROUP ESPAÑA DISTR., S.A. & 84,5 & $2,0 \%$ \\
\hline 2 & EL CORTE INGLES, S.A. & 74,0 & $1,7 \%$ \\
\hline 3 & L' OREAL ESPAÑA, S.A. & 69,6 & $1,6 \%$ \\
\hline 4 & PSAG AUTOMOVILES COMER.ESPAÑA, S.A. (CITROEN) & 67,9 & $1,6 \%$ \\
\hline 5 & PROCTER \& GAMBLE ESPAÑA, S.A. & 67,0 & $1,6 \%$ \\
\hline 6 & ORANGE ESPAGNE, S.A. & 64,3 & $1,5 \%$ \\
\hline 7 & LINEA DIRECTA ASEGURADORA, S.A. & 59,7 & $1,4 \%$ \\
\hline 8 & TELEFONICA, S.A.U. & 52,6 & $1,2 \%$ \\
\hline 9 & MUTUA MADRILEÑA AUTOMOVILISTA, S.A. & 49,8 & $1,2 \%$ \\
\hline 10 & VODAFONE ESPAÑA, S.A.U. & 49,6 & $1,2 \%$ \\
\hline 11 & ORGANIZACION NACIONAL CIEGOS ESPAÑ. & 49,0 & $1,1 \%$ \\
\hline 12 & CIA.SERV.BEB.REFRESC.SL(COCA COLA) & 45,7 & $1,1 \%$ \\
\hline 13 & SEAT, S.A. & 45,4 & $1,1 \%$ \\
\hline 14 & SAMSUNG ELECTRONIC IBERIA, S.A. & 42,8 & $1,0 \%$ \\
\hline 15 & RENAULT ESPAÑA COMERCIAL, S.A. & 40,0 & $0,9 \%$ \\
\hline 16 & FORD ESPAÑA, S.L. & 38,4 & $0,9 \%$ \\
\hline 17 & SECURITAS DIRECT ESPAÑA, S.A.U. & 35,4 & $0,8 \%$ \\
\hline 18 & OPEL ESPAÑA, S.L. & 34,4 & $0,8 \%$ \\
\hline 19 & TOYOTA ESPAÑA, S.L.U. & 34,0 & $0,8 \%$ \\
\hline 20 & AMAZON EU SARL SUCURSAL EN ESPAÑA & $\mathbf{2 7 , 9}$ & $0,7 \%$ \\
\hline & TOTAL 2O PRIMEROS & & $24,2 \%$ \\
\hline & & & \\
\hline
\end{tabular}

Fuente: Elaboración propia a partir de Infoadex (2020)

\subsection{Descripción, Unidades de contexto y de registro seleccionadas}

Este estudio se fundamenta en el análisis de contenido basado en el estudio de categorías de unidades léxicas presentes en el copy de los anuncios que conforman las unidades de contexto.

Con el análisis de contenido se procura analizar y comparar de una forma exploratoria los mensajes publicitarios vinculados a la época de pandemia como parte de la realidad actual como afirma Krippendorff "el análisis de contenido tiene una orientación fundamentalmente empírica, exploratoria, vinculada a fenómenos reales y de finalidad predictiva" (1990, p. 10). Aunque hoy en día, no sólo se orienta a fenómenos reales sino a fenómenos audiovisuales creados y cinéticos como se puede apreciar en el análisis de contenido que hacen López, San José y Núñez-Cansado (2020) en su artículo relativo al universo del lujo en la filmografía de Pedro Almodóvar, donde se consigue una representación significativa real extraída de historias "irreales" de sus películas. 
El estudio se fundamenta inicialmente en extraer datos cuantitativos, pero sin dejar de observar la significación de esos datos, como afirma López Noguero (2002), a medida que se van analizando datos se van descubriendo rasgos cualitativos como reacciones, novedades que sin duda no se pueden dejar pasar. Unos datos, irremediablemente, llevan a otros.

Existen dos principales categorías de unidades de contexto que serán utilizadas posteriormente para realizar el estudio comparativo. El criterio de selección de las unidades de contexto se centra en un primer grupo (Grupo 1) compuesto por un corpus de 15 spots de los principales inversores en publicidad en España durante el 2019, seleccionados debido a la transparencia informativa en sus diferentes canales de comunicación, como son sus páginas web, canales de YouTube, etc., y entre los que se encuentran los siguientes anunciantes: Volkswagen, El Corte Inglés, L’Oreal, H\&S (representando a P\&G), Orange, Línea Directa Aseguradora, Telefónica (Movistar), Mutua Madrileña, Vodafone, Grupo Social ONCE, Coca Cola, Seat, Securitas Direct, Opel y Amazon.

Se establecen como unidades de contexto los copies de los 30 anuncios seleccionados que, a su vez, tienen unas unidades de registro que serán aquellas palabras seleccionadas dentro del estudio. A continuación, se ha elaborado un listado con el corpus y los spots seleccionados que conforman esa muestra, que estarán categorizadas como unidades de contexto en el grupo 1:

1. Volkswagen. "Felices los 3". 2 abril 2019.

2. El Corte Ingles. "Ya están aquí \#lasrebajas más refrescantes del verano “. 28 junio 2019.

3. L’Oréal. "No hay barreras entre tu piel y tu maquillaje " 11 noviembre 2019

4. H\&S. "Leyendas del mañana". 8 febrero de 2019.

5. Orange. "Las princesas no comen". 25 sept. 2019

6. Línea Directa Aseguradora. "Hemos provocado un seísmo" 25 febrero 2019.

7. Movistar. "Reinventa tu hogar con movistar home". 27 noviembre 2019.

8. Mutua madrileña. "Vamos mútuate".5 nov 2019.

9. Vodafone. "¿Pasamos más tiempo con el móvil que con nuestros seres queridos?". 19 diciembre 2019.

10. Fundación ONCE. “La ilusión puede con todo". 2 diciembre 2019.

11. Coca Cola. "Es hora de juntarnos para comer". 10 febrero 2019.

12. Seat. "Nuevo Seat Terraco. Sigue sumando". 10 noviembre 2019.

13. Securitas Direct. "Tu alarma para el hogar, tu negocio y las personas" 5 noviembre 2019.

14. Opel. "Nuevo Opel Corsa". 15 noviembre 2019.

15. Amazon. “Amazon Echo. Mi gran noche”. Junio 2019

Para el año del 2020 se han seleccionado anuncios que hubiesen sido emitidos a partir del 15 de marzo, fecha en la que se produjo el confinamiento debido al estado de alarma. 
1. Volkswagen. "Te mereces un fin de semana con la gama California”. Emitido el 2 de abril 2020.

2. El Corte Ingles. “4 días de los grandes descuentos”. 18 de junio 2020.

3. L'Oréal. "Disfruta la belleza de volver". 13 de julio de 2020.

4. H\&S. "Sigamos Adelante". 15 abril 2020.

5. Orange. “La tecnología no sustituye a los que más quieres”. 20 marzo 2020.

6. Línea directa aseguradora. "Seguro de Hogar con pago fraccionado" 20 abril 2020.

7. Movistar. "Cuando estamos conectados somos capaces de hacer cosas increíbles." 27 marzo 2020.

8. Mutua madrileña. "Cuida de ti y de los tuyos". 20 marzo 2020.

9. Vodafone. "Protejámoslos, protegiéndonos todos". 18 marzo 2020.

10. ONCE. Grupo social ONCE. “La ilusión puede con todo” 20 marzo 2020.

11. Coca Cola. "Volveremos para apreciar nuestros bares". 17 agosto 2020.

12. Seat. "llevamos años moviéndonos juntos" 25 marzo 2020.

13. Securitas Direct España. "Protegemos personas". 23 abril 2020.

14. Opel. "Nuestro compromiso: seguir en marcha por ti". 16 abril 2020.

15. Amazon Eu España. ¿Qué estamos haciendo? 28 mayo 2020.

El grupo 2, se establece con las unidades de registro extraídas de los mensajes publicitarios del corpus seleccionado. Palabras que pudieran tener una importancia significativa, relevante o identificativa como parte del cambio de la estrategia comunicativa de algunas de estas empresas, que se engloban entre las más importantes del panorama económico español. Unidades de registro son el grupo 2: ahora; ayudar; casa; COVID; cuidar (se); esto/s; ir; juntos; momentos; nuevo; nunca; pandemia; proteger (se); quedar (se); resistir; seguir; todo/s; venir; virus; volver.

La relación de todas ellas se presenta a continuación por orden alfabético. Se aportan sus significados, de acuerdo con la Real Academia Española, para continuar con una descripción de tipo asociativo según su tratamiento en los mensajes publicitarios.

Ahora. Adverbio de tiempo que representa un momento actual. Podría significar el estado actual de crisis sanitaria, de pandemia; o quizá una época o estación del año, verano, primavera, etc. Todo dependerá del contexto para darle uno u otro significado.

Ayudar. Verbo que significa auxiliar, socorrer, prestar cooperación. En este sentido las marcas los están usando para ofrecer servicios más fáciles durante la época sanitaria, favorecer tanto económica, como socialmente la vida de las personas. Como por ejemplo "Te ayudamos con un 30\% de descuento" (L'Oréal), "ofrecemos nuestra ayuda contra la pandemia" (Opel)... 
Casa. Vivienda. Edificio para evitar. Esta palabra ha sido muy importante y utilizada porque una de las medidas de protección contra el virus era quedarse en casa para no contagiarse a uno mismo y a los demás. De hecho, se ha vivido un confinamiento domiciliario, desconocido para muchos de nosotros. Es una de las palabras más usadas durante el año 2020 pues se crearon varios hashtags con el mensaje \#quedateencasa, \#yomequedoencasa, etc.

COVID. Síndrome respiratorio agudo producido por un coronavirus. En esta ocasión se habla de la COVID-19 porque es provocada por el contagio del virus SARS$\mathrm{CoV}-2$.

Cuidar (se). Asistir, guardar, conservar. Vivir con advertencia respecto de algo. En la publicidad sería exactamente lo mismo, cuidar a un enfermo, mirar por tu propia salud, intentar no contagiarse del virus. Como bien dice la Mutua Madrileña "Mientras nosotros cuidamos de vosotros. Queremos que nos hagas una promesa. Que cuidarás de ti y de los tuyos."

Esto/s. Adjetivo demostrativo. Que está cerca de la persona que habla. Que se acaba de mencionar, o que se va a mencionar a continuación. Dicho de un periodo de tiempo, de un momento o de un lugar: En el que se encuentra quien habla. Sin embargo, los anunciantes lo están usando prioritariamente como locución adverbial, en las que esto, se usa como eufemismo para referirse a la actual situación, el problema, la crisis, la enfermedad.

Ir. Caminar de acá para allá. Moverse de un lugar a otro apartado de la persona que habla. En estas categorías textuales, se usa sobre todo como parte de la acción del verbo que conjuga.

Juntos. Adjetivo. Unido, cercano. Adverbio. Juntamente, cerca al lado. En estos mensajes publicitarios destaca como todos unidos, a la vez, por ejemplo, como dice Opel "Porque solo juntos venceremos a este virus". Juntos, haciendo cosas que nos favorezcan a todos, cumpliendo las normas de comportamiento, de protección, etc.

Momentos. Lapso de tiempo más o menos largo que se singulariza por cualquier circunstancia. Cualquier tiempo considerado como actual o presente. En estos textos se suele usar En estos momentos que sería una locución adverbial que significa en un tiempo concreto, específicamente un tiempo definido de crisis sanitaria, de muertes, de pérdidas económicas... como indica Orange "En Orange sabemos que la tecnología no sustituye a las personas, pero en estos momentos haremos todo lo posible por acercarte a ellas"

Nuevo. Adjetivo. Recién hecho, fabricado. Es una palabra que se usa mucho en publicidad cuando se quiere anunciar o informar del lanzamiento de un producto novedoso, actual y eso ocurre muy a menudo, sobre todo con ciertas marcas que hacen uso de la publicidad en el momento de introducción de productos en el mercado. Por ejemplo, cuando SEAT anuncia el "nuevo Seat Terraco por $26.400 €^{\prime \prime}$ 
Análisis lexicométrico de los mensajes publicitarios de las grandes marcas en España ante la crisis del COVID

Nunca. Adverbio temporal. El uso de esta palabra en estos spots distingue atributos o circunstancias inéditas dándole énfasis a la frase como en la expresión de Vodafone "Ahora más que nunca estamos con nuestros mayores"

Pandemia. Enfermedad epidémica que se extiende a muchos países o que ataca a casi todos los individuos de una localidad o región. En esta publicidad, significa exactamente lo mismo que dice la RAE, en esta ocasión, provocada por el virus SARSCoV-2.

Proteger (se). Verbo transitivo. Resguardar a una persona, animal o cosa de un perjuicio o peligro, poniéndole algo encima, rodeándolo, etc. Amparar, favorecer, defender a alguien o algo. En este análisis se ha entendido de igual manera, proteger, amparar al desfavorecido, a nosotros mismos del contagio del virus.

Quedar (se). Verbo intransitivo que indica estar, detenerse forzosa o voluntariamente en un lugar. Dicho de una persona o de una cosa: permanecer en su estado, o pasar a otro más o menos estable. En este estudio quiere decir básicamente lo mismo, permanecer en casa para permanecer seguros, a salvo como también indica Seat en su publicidad "Parar ahora es pensar en los demás. Es seguir las recomendaciones. Es, por encima de todo, quedarse en casa".

Resistir. Verbo que significa tolerar, aguantar o sufrir. En este contexto significa oponerse con fuerza al ataque del virus.

Seguir. Verbo. Proseguir o continuar lo empezado. Esto quiere decir que sigamos cuidándonos, luchando contra el virus, que, aunque el mundo se pare, las marcas o las empresas nos van a continuar ayudando, van a respaldar sus productos, etc. como dice Vodafone "Seguiremos estando disponibles en nuestra web"; o "Nuestro compromiso. Seguir en marcha" (Opel)

Todo/s. Adjetivo indefinido que significa entero o en su totalidad. Indica que la persona o cosa denotada por el sustantivo al que modifica cumple todos los atributos que se asocian con un prototipo. En este sentido, se puede decir que la aplicación de esta palabra en los textos implica a un conjunto de cosas o personas que se asocian contra un problema. Vuelve a usarse como eufemismo del problema, del virus... "porque cuando todo esto pase" (Volkswagen). O bien a la unión en conjunto de la sociedad para denotar que la población unida si seguimos las recomendaciones podremos superar este estado de crisis. "protejámoslos, protegiéndonos todos" (Vodafone).

Venir. Verbo intransitivo. Dicho de una persona o de una cosa: llegar a donde está quien habla. Se utiliza como una manera de acercarse al comunicador. Como dice Telefónica "ven a tu tienda Movistar a probarlo"

Virus. Organismo de estructura muy sencilla, compuesto de proteínas y ácidos nucleicos, y capaz de reproducirse solo en el seno de células vivas específicas, 
utilizando su metabolismo. Hace referencia al virus SARS-CoV-2 que provoca la enfermedad por coronavirus (COVID-19).

Volver. Verbo transitivo. Poner o constituir nuevamente a alguien o algo en el estado que antes tenía. Cuando se habla de volver, en estos anuncios, significa recuperar nuestra vida, nuestro estado anterior al estado de crisis sanitario como indica Línea Directa "Línea Directa te ayuda para cuando tu casa vuelva a ser solo tu casa" o la Mutua Madrileña "Todo volverá a la normalidad. Hasta entonces, quédate en casa."

Se pueden diferenciar dos etapas durante el análisis: la primera se basa en recabar los datos relativos a los copy de los anuncios del año 2019 que conforman el corpus, y repetir la misma operación con aquellos que surgieron a raíz del confinamiento domiciliario desde el estado de alarma de marzo de 2020.

La segunda etapa, se distingue por transcribir el contenido textual publicitario para poder computar y analizar las palabras de mayor uso en ambos intervalos de tiempo, analizar las preferencias, usos en cada uno de los anunciantes, y comprobar finalmente si se cumple el objetivo principal de este estudio.

\subsection{Recogida y análisis de datos}

Categorías de análisis: Se aplica el criterio de restricción marcando como palabras vacías: marcas, artículos, preposiciones, conjunciones, pronombres personales, e incidencia ponderada menor a 3 en el cómputo total de su uso, a excepción de las unidades léxicas virus, pandemia y COVID por su relevancia con el tema y por el escaso uso de estas en los mensajes publicitarios analizados.

Se selecciona una categoría léxica de análisis que consta de 25 términos. De esa selección se hace un cribado de las unidades léxicas que no aparecen con una frecuencia de uso mayor a 3 unidades en el sumatorio de los mensajes de ambos años. Por ese motivo, el cómputo total de palabras seleccionadas queda reducido a 20, dejando así 5 fuera del análisis.

Tomando como referencia las tablas léxicas de (Pardo, 2000) en su Análisis de la métrica en aplicaciones de la estadística textual a la tipología de trayectorias se ha clasificado la información incluyéndola en dos tablas diferentes, una para cada año. En estas se puede apreciar la frecuencia de uso de las unidades léxicas dentro de las unidades de contexto seleccionadas. (Tabla 2 y Tabla 3 en Anexos).

En la columna izquierda se pueden apreciar todos los elementos del grupo 1 y en la fila superior las unidades de registro del grupo 2.

Se han elaborado tablas léxicas para poder establecer comparaciones y conexiones entre los elementos del grupo 1 con los del 2 de una manera práctica y eficaz. Una tabla léxica, lo define Elías Pardo como "una tabla de contingencia que cruza las respuestas con las formas gráficas o palabras que cada individuo utiliza en su respuesta. En el 
caso de los itinerarios, una fila de la tabla léxica contiene la frecuencia de aparición de cada una de las palabras código en cada trayectoria" (2000, p. 2). Pero el significado concreto que se da a cada tabla depende de los contenidos. En este caso, se ha decidido no codificar los datos, para que se puedan identificar los campos y poder reconocer los textos de los anuncios que más adelante se exponen. Además, no se usarán programas informáticos que necesiten de códigos o etiquetas para categorizar las unidades de registro. En este estudio, tampoco será necesaria una categorización muy exhaustiva, ya que el volumen de datos no es muy elevado y la información se ha establecido atendiendo a dos grupos claramente diferenciados: grupo 1 (unidades de contexto representadas a través del anunciante), y grupo 2 (unidades de registro representadas por los términos seleccionados).

\section{ANÁLISIS Y DISCUSIÓN}

\subsection{Análisis cuantitativo exploratorio}

A partir del análisis léxico de ambos años (2019-2020) se han identificado un total de 1798 palabras; 1063 se corresponden con los anuncios del 2019 y 735 con los del 2020. De entre todas ellas, se han seleccionado aquellas que tenían una frecuencia de uso mayor a 3, a excepción de las palabras pandemia, virus y COVID, que se ha decidido mantenerlas en el estudio por su baja representación y su relevancia en el estado actual de crisis sanitaria mundial.

Tras someter al corpus al cómputo de las unidades de registro seleccionadas, se han podido observar varias cuestiones:

Existe un mayor promedio del porcentaje del uso del léxico seleccionado en el estudio del 2020, un $12,79 \%$ con una media de 6,27 unidades de registro usadas por spot, que en el del 2019 que se queda en un 3,39\% con tan solo la incorporación de 2,40 palabras por spot, a pesar de que el numero total de palabras utilizadas en el 2020 es inferior (735), frente a las 1063 que el año que le precede. La media de las palabras por spot en 2019 asciende a 70,87 frente a las 49 que se usan en el 2020.

En el 2019 se pueden apreciar varios puntos de interés:

El spot más corto del corpus seleccionado es el de H\&S. Con un total de 17 palabras de unidades de contexto, tan solo han empleado una palabra de la selección "nuevo" que no implica mayor significado que el que se usa para dar a conocer un producto desconocido dentro de una gama ya establecida como es el champú anticaspa de H\&S. En este anuncio se ha mantenido una estrategia de comunicación comercial donde se hace hincapié en uno de los atributos específicos de este producto, que es la eliminación de la caspa. (Ver tabla 2 y 3 en anexos)

"Preparando a las leyendas del mañana. Nuevo HES. Que nada te pare. Y menos la caspa. \#CONLACABEZAALTA".

(YouTube. H\&S España. 2019). 
El spot más largo, entre todo el corpus seleccionado, es el de L’'Oréal que realiza un spot de 84 segundos con 172 palabras, de las cuales, tan solo 2 unidades de registro y alcanzando tan solo un 1,16\% sobre el total del texto, quedando por debajo de la media que es de un 3,39. El término empleado en el verbo "ir" que significativamente no aporta nada ya que, simplemente, forma parte de la acción del verbo que conjuga.

“Sin barreras significa sin límites, no tengo límites. Nadie me pone límites, significa que no tengo que esconderme o cambiar lo que me hace ser yo. Yo. Significa que un "No Puedo" no puede pararme. Significa que puedo ser lo que me proponga. Yo decido quién soy, quién quiero ser y quién voy a ser. Un “no puedes" no va a detenerme, porque nada me detiene, puedo desafiar cualquier norma y romper cualquier techo. Sin olvidar mi historia, sin renunciar a mi verdad, a mi historia..."

(YouTube. L’Oréal Paris España. 2019)

Vodafone y Coca Cola son quienes hacen mayor uso de las unidades de registro con un total de 7 y 4 inserciones respectivamente, que, aunque no es un número elevado, son los que acumulan también mayor porcentaje de uso con un $7,53 \%$ y un $8,16 \%$, respectivamente. Este dato difiere mucho de la parte opuesta de la tabla, ya que hay nada menos que 5 unidades de contexto que disponen tan solo de 1 unidad de registro; H\&S, Amazon, Telefónica (Movistar), El Corte Inglés y Línea Directa estando sus porcentajes de uso entre 1,27\%-1,89\% quedando por debajo de la media, del 3,39\%. (Ver tabla 4).

Tabla 4. Unidades de registro más utilizadas por anunciante en el 2019

\begin{tabular}{|c|c|c|c|c|}
\hline & & $\begin{array}{l}\text { TOTAL (Ud. R.) } \\
\text { USADAS }\end{array}$ & $\begin{array}{c}\text { TOTAL PALABRAS } \\
\text { ANUNCIO }\end{array}$ & $\%$ \\
\hline 1 & VODAFONE & 7 & 93 & 7,53 \\
\hline 2 & COCA COLA & 4 & 49 & 8,16 \\
\hline 3 & OPEL & 3 & 50 & 6,00 \\
\hline 4 & SECURITAS DIRECT & 3 & 63 & 4,76 \\
\hline 5 & ONCE & 3 & 89 & 3,37 \\
\hline 6 & ORANGE & 3 & 105 & 2,86 \\
\hline 7 & SEAT & 2 & 42 & 4,76 \\
\hline 8 & MUTUA MADRILEÑA & 2 & 52 & 3,85 \\
\hline 9 & VOLKSWAGEN & 2 & 69 & 2,90 \\
\hline 10 & L'OREAL & 2 & 172 & 1,16 \\
\hline 11 & H\&S & 1 & 17 & 5,88 \\
\hline 12 & AMAZON & 1 & 53 & 1,89 \\
\hline 13 & TELEFÓNICA & 1 & 64 & 1,56 \\
\hline 14 & EL CORTE INGLES & 1 & 66 & 1,52 \\
\hline 15 & LINEA DIRECTA & 1 & 79 & 1,27 \\
\hline & SUMA & 36 & 1063 & 3,39 \\
\hline
\end{tabular}

Fuente: Elaboración propia

A continuación, se pueden apreciar las Ud. R que ha utilizado Vodafone en su anuncio del 2019:

- ¿Nunca te vas a venir a vivir conmigo no? 
Análisis lexicométrico de los mensajes publicitarios de las grandes marcas en España ante la crisis del COVID

- ¿Y tu qué, nunca te vas a quedar?

- Toma

- ¿Qué me regalas, un cacharro de estos?

- Si papá, un teléfono.

Tiempo de uso: Has usado un 34\% más el móvil....

(YouTube, Vodafone España. 2019)

Tampoco son representativas estas palabras ya que, en este anuncio, lo que encarna es justo lo que quiere decir. No tienen un valor significativo extra. Podemos destacar de este anunciante que es el que más unidades de registro diferentes usa con un total de 5 sobre 7 equivalente a un 71,43\% de variación de sus registros. Sin embargo, Coca Cola baja su diferenciación un $50 \%$ ya que usa 4 términos, pero con tan solo 2 variables. (Ver tabla 5).

Tabla 5. Porcentajes de uso de diferentes unidades de registro por spot en 2019

\begin{tabular}{|c|c|c|c|c|}
\hline & & \begin{tabular}{|l} 
TOTAL DIFERENTES \\
(Ud. R.) USADAS
\end{tabular} & $\begin{array}{l}\text { TOTAL (Ud. R.) } \\
\text { USADAS }\end{array}$ & $\%$ \\
\hline 1 & ONCE & 3 & 3 & 100,00 \\
\hline 2 & ORANGE & 3 & 3 & 100,00 \\
\hline 3 & SEAT & 2 & 2 & 100,00 \\
\hline 4 & MUTUA MADRILEÑA & 2 & 2 & 100,00 \\
\hline 5 & H\&S & 1 & 1 & 100,00 \\
\hline 6 & AMAZON & 1 & 1 & 100,00 \\
\hline 7 & TELEFÓNICA & 1 & 1 & 100,00 \\
\hline 8 & EL CORTE INGLES & 1 & 1 & 100,00 \\
\hline 9 & LINEA DIRECTA & 1 & 1 & 100,00 \\
\hline 10 & VODAFONE & 5 & 7 & 71,43 \\
\hline 11 & OPEL & 2 & 3 & 66,67 \\
\hline 12 & SECURITAS DIRECT & 2 & 3 & 66,67 \\
\hline 13 & COCA COLA & 2 & 4 & 50,00 \\
\hline 14 & VOLKSWAGEN & 1 & 2 & 50,00 \\
\hline 15 & L'OREAL & 1 & 2 & 50,00 \\
\hline & SUMA & 28 & 36 & 77,78 \\
\hline
\end{tabular}

Fuente: Elaboración propia

También se puede apreciar que un total de 9 unidades de contexto obtienen un porcentaje del 100\% de variedad entre sus Ud. R., donde son destacables, ONCE y Orange con 3 unidades de registro diferentes sobre un total de 3 empleadas.

No obstante, en el 2019 la unidad de registro más usada es el verbo "venir" con 7 apariciones, seguida de "ir" con 6 inserciones y de "nuevo" con 5.

También se puede apreciar, durante el mismo año, que hay 8 palabras con una incidencia del $0 \%$ de uso como son "ahora", "COVID", "cuidar/se", "momentos", "pandemia", "proteger/se", "resistir" y "virus". (Ver tabla 6). En esta ocasión, es bastante evidente que no se usen las palabras como "virus", "pandemia" y "COVID" 
Sánchez Sandoval, R.

Análisis lexicométrico de los mensajes publicitarios de las grandes marcas en España ante la crisis del COVID

porque, a parte de tener unas connotaciones negativas, aún no estábamos en situación de crisis sanitaria.

Por otra parte, el verbo más usado es "venir", que implica el hecho de invitar al espectador a acudir a algún sitio para ver o conocer el producto, como por ejemplo en el texto de Opel que anuncia el nuevo Corsa:

Ingeniería alemana, diseño sofisticado. Interior con tecnología Premium. Innovación en seguridad que ilumina el camino hacia el futuro. Sí, es divertido hablar de ello, pero es mucho más divertido conducirlo. Nuevo Opel corsa. Ven a conocer el nuevo Opel corsa en los Corsa Days del 21 al 23 de noviembre.

(YouTube. Opel España, 2019)

Sin embargo, si se tienen en cuenta los porcentajes, es Coca Cola la que mayor porcentaje de uso de $\mathrm{Ud}$. R obtiene con un $8,16 \%$ registrado sobre el total de palabras usadas en el copy:

Occidente está lleno de comida china, y todo el mundo la entiende

La comida mexicana llega a todas partes, y no hay muro que contenga

Cuando el mundo decide con la cabeza, se separa.

Cuando el mundo decide con el estómago, se junta.

Es hora de juntarnos a comer.

(YouTube, Coca Cola, 2019)

Tabla 6. Frecuencia del uso de las unidades de registro en los anuncios del 2019

\begin{tabular}{|c|l|c|}
\hline \multicolumn{2}{|c|}{ UNIDADES DE REGISTRO } & 2019 \\
\hline 1 & VENIR & 7 \\
\hline 2 & IR & 6 \\
\hline 3 & NUEVO & 5 \\
\hline 4 & TODO/S & 4 \\
\hline 5 & JUNTOS & 3 \\
\hline 6 & NUNCA & 2 \\
\hline 7 & QUEDAR/SE & 2 \\
\hline 8 & SEGUIR & 2 \\
\hline 9 & VOLVER & 2 \\
\hline 10 & AYUDA/R & 1 \\
\hline 11 & CASA & 1 \\
\hline 12 & ESTO/S & 1 \\
\hline 13 & AHORA & 0 \\
\hline 14 & COVID & 0 \\
\hline 15 & CUIDAR/SE & 0 \\
\hline 16 & MOMENTOS & 0 \\
\hline 17 & PANDEMIA & 0 \\
\hline 18 & PROTEGER/SE & 0 \\
\hline 19 & RESISTIR & 0 \\
\hline 20 & VIRUS & 0 \\
\hline & & \\
\hline
\end{tabular}

Fuente: Elaboración propia 
Sánchez Sandoval, R.

Análisis lexicométrico de los mensajes publicitarios de las grandes marcas en España ante la crisis del COVID

En este texto se puede apreciar cómo hay $4 \mathrm{Ud}$. R, pero tan solo 2 variantes, ya que ambas se repiten, por lo que tampoco son demasiado significativas las connotaciones del texto. (Ver tabla 7) Con este spot, se puede apreciar que este mensaje en el 2020 sería imposible emitirlo por una de las normas preventivas de contagio impuestas por el Gobierno, como es la de no juntarse con x personas. (Dependiendo del momento de incidencia de casos acumulados, era mayor o menor número de personas con las que no debíamos juntarnos).

Tabla 7. Porcentaje de las unidades de registro de anunciantes del 2019

\begin{tabular}{|c|l|c|c|c|}
\hline & & $\begin{array}{c}\text { TOTAL (Ud. R.) } \\
\text { USADAS }\end{array}$ & $\begin{array}{c}\text { TOTAL PALABRAS } \\
\text { ANUNCIO }\end{array}$ & $\%$ \\
\hline 1 & COCA COLA & 4 & 49 & 8,16 \\
\hline 2 & VODAFONE & 7 & 93 & 7,53 \\
\hline 3 & OPEL & 3 & 50 & 6,00 \\
\hline 4 & H\&S & 1 & 17 & 5,88 \\
\hline 5 & SECURITAS DIRECT & 3 & 63 & 4,76 \\
\hline 6 & SEAT & 2 & 42 & 4,76 \\
\hline 7 & MUTUA MADRILENA & 2 & 52 & 3,85 \\
\hline 8 & ONCE & 3 & 89 & 3,37 \\
\hline 9 & VOLKSWAGEN & 2 & 69 & 2,90 \\
\hline 10 & ORANGE & 3 & 105 & 2,86 \\
\hline 11 & AMAZON & 1 & 53 & 1,89 \\
\hline 12 & TELEFÓNICA & 1 & 64 & 1,56 \\
\hline 13 & EL CORTE INGLES & 1 & 66 & 1,52 \\
\hline 14 & LINEA DIRECTA & 1 & 79 & 1,27 \\
\hline 15 & L'OREAL & 2 & 172 & 1,16 \\
\hline & \multicolumn{1}{|c|}{ SUMA } & 36 & 1063 & 3,39 \\
\hline
\end{tabular}

Fuente: Elaboración propia

En el año 2020, ya se van a ir apreciando algunas diferencias respecto al año anterior. Siguiendo el mismo esquema de análisis del 2019, el spot más corto extraído del corpus es el de Volkswagen con tan solo 18 palabras en su copy. (Ver tabla 2) Con 5 sobre 18 palabras, obtiene el mayor porcentaje de uso de unidades de registro por anuncio con un $27,78 \%$, muy por encima de la media que es $12,79 \%$. (Ver tabla 8 ) 
Sánchez Sandoval, R.

Análisis lexicométrico de los mensajes publicitarios de las grandes marcas en España ante la crisis del COVID

Tabla 8. Porcentajes de Ud. R. en los anuncios del 2020

\begin{tabular}{|c|l|c|c|c|}
\hline & & $\begin{array}{c}\text { TOTAL (Ud.R.) } \\
\text { USADAS }\end{array}$ & $\begin{array}{c}\text { TOTAL PALABRAS } \\
\text { ANUNCIO }\end{array}$ & $\%$ \\
\hline 1 & VOLKSWAGEN & 5 & 18 & 27,78 \\
\hline 2 & MUTUA MADRILENA & 7 & 30 & 23,33 \\
\hline 3 & SEAT & 11 & 54 & 20,37 \\
\hline 4 & ORANGE & 8 & 41 & 19,51 \\
\hline 5 & VODAFONE & 6 & 31 & 19,35 \\
\hline 6 & SECURITAS DIRECT & 7 & 43 & 16,28 \\
\hline 7 & OPEL & 15 & 117 & 12,82 \\
\hline 8 & LINEA DIRECTA & 7 & 57 & 12,28 \\
\hline 9 & COCA COLA & 7 & 63 & 11,11 \\
\hline 10 & L'OREAL & 7 & 64 & 10,94 \\
\hline 11 & H\&S & 4 & 42 & 9,52 \\
\hline 12 & ONCE & 4 & 55 & 7,27 \\
\hline 13 & AMAZON & 3 & 53 & 5,66 \\
\hline 14 & TELEFÓNICA & 1 & 20 & 5,00 \\
\hline 15 & EL CORTE INGLES & 2 & 47 & 4,26 \\
\hline & SUMA & 94 & 735 & 12,79 \\
\hline
\end{tabular}

Fuente: Elaboración propia

Sin embargo, tan solo usa 3 variantes sobre 5 con lo que su porcentaje se reduce a un $60 \%$ como se puede apreciar en la tabla 9. Además, como se puede ver a continuación, el contenido del mensaje es totalmente representativo en este momento de crisis ya que implica algunas de las palabras más significativas inmersas en el contexto de crisis por la COVID:

Resistid, amigos, resistid.

Porque cuando todo esto pase, podréis pasar un finde con la gama California.

Participa \#GraciasPorResistir

(YouTube, Volkswagen, 2020) 
Sánchez Sandoval, R.

Análisis lexicométrico de los mensajes publicitarios de las grandes marcas en España ante la crisis del COVID

Tabla 9. Porcentajes de uso de diferentes Ud. R. en los anuncios del 2020

\begin{tabular}{|c|c|c|c|c|}
\hline & & $\begin{array}{l}\text { TOTAL (Ud. R.) } \\
\text { DIFERENTES } \\
\text { USADAS }\end{array}$ & $\begin{array}{c}\text { TOTAL PALABRAS } \\
\text { USADAS }\end{array}$ & $\%$ \\
\hline 1 & $H \& S$ & 4 & 4 & 100,00 \\
\hline 2 & AMAZON & 3 & 3 & 100,00 \\
\hline 3 & EL CORTE INGLES & 2 & 2 & 100,00 \\
\hline 4 & TELEFÓNICA & 1 & 1 & 100,00 \\
\hline 5 & MUTUA MADRILEÑA & 6 & 7 & 85,71 \\
\hline 6 & VODAFONE & 5 & 6 & 83,33 \\
\hline 7 & SEAT & 9 & 11 & 81,82 \\
\hline 8 & ORANGE & 6 & 8 & 75,00 \\
\hline 9 & LINEA DIRECTA & 5 & 7 & 71,43 \\
\hline 10 & COCA COLA & 5 & 7 & 71,43 \\
\hline 11 & VOLKSWAGEN & 3 & 5 & 60,00 \\
\hline 12 & SECURITAS DIRECT & 4 & 7 & 57,14 \\
\hline 13 & L'OREAL & 4 & 7 & 57,14 \\
\hline 14 & OPEL & 8 & 15 & 53,33 \\
\hline 15 & ONCE & 2 & 4 & 50,00 \\
\hline & SUMA & 67 & 94 & 71,28 \\
\hline
\end{tabular}

Fuente: Elaboración propia

El spot de Opel, con 117 palabras, se convierte en el más largo de todo el corpus de ese año. Pero también el que más unidades de registro emplea, un total de 15, obteniendo un $12,82 \%$, unas décimas por encima de la media de porcentajes de uso del 12,79\% (ver tabla 8). Ha utilizado 8 variantes de las 15 Ud. R., lo que implica un 53,33\% reduciendo algo su porcentaje sobre el total (ver tabla 9).

En Opel seguimos en marcha. Para que los que mas nos necesitan nunca se detengan. Por eso estamos comprometidos a: garantizar la movilidad del personal sanitario. Estar cerca en la distancia. Seguir siendo parte de la cadena que hace que todo funcione. Volver a recorrer muchos kilómetros juntos. Ofreceros nuestra ayuda contra la pandemia. Desinfectando los coches de la Policía local, el centro de salud y la Guardia Civil. Que las enfermeras puedan continuar. Estar listos para la vuelta. Porque siempre estamos contigo, abiertos, cerrados, online. Porque solo juntos venceremos a este virus. Porque juntos somos más fuertes en las buenas y en las malas. Seguimos aquí, por vosotros, por todos. Este es nuestro mayor compromiso. \#OPELOPEN.

(YouTube. Opel España, 2020)

En este anuncio se puede apreciar también cómo el contexto es esencial para entender el contenido de este. Opel incluye una de las palabras más significativas de esta época virus, que, con el resto de la unidad de contexto, demuestra que ha cambiado su estrategia comunicativa adaptando el mensaje al momento actual. 
Sánchez Sandoval, R.

Análisis lexicométrico de los mensajes publicitarios de las grandes marcas en España ante la crisis del COVID

Tabla 9. Porcentajes de uso de diferentes Ud. R. en los anuncios del 2020

\begin{tabular}{|c|l|c|c|c}
\hline & & $\begin{array}{c}\text { TOTAL (Ud.R.) } \\
\text { USADAS }\end{array}$ & $\begin{array}{c}\text { TOtAL PALABRAS } \\
\text { ANUNCIO }\end{array}$ & $\%$ \\
\hline 1 & OPEL & 15 & 117 & 12,82 \\
\hline 2 & SEAT & 11 & 54 & 20,37 \\
\hline 3 & ORANGE & 8 & 41 & 19,51 \\
\hline 4 & MUTUA MADRILENA & 7 & 30 & 23,33 \\
\hline 5 & SECURITAS DIRECT & 7 & 43 & 16,28 \\
\hline 6 & LINEA DIRECTA & 7 & 57 & 12,28 \\
\hline 7 & COCA COLA & 7 & 63 & 11,11 \\
\hline 8 & L'OREAL & 7 & 64 & 10,94 \\
\hline 9 & VODAFONE & 6 & 31 & 19,35 \\
\hline 10 & VOLKSWAGEN & 5 & 18 & 27,78 \\
\hline 11 & H\&S & 4 & 42 & 9,52 \\
\hline 12 & ONCE & 4 & 55 & 7,27 \\
\hline 13 & AMAZON & 3 & 53 & 5,66 \\
\hline 14 & EL CORTE INGLES & 2 & 47 & 4,26 \\
\hline 15 & TELEFÓNICA & 1 & 20 & 5,00 \\
\hline \multicolumn{2}{|c|}{ SUMA } & 94 & 735 & 12,79 \\
\hline
\end{tabular}

Fuente: Elaboración propia

El segundo anunciante con más Ud. R. utilizadas es Seat con 11 palabras de un copy de 54 con 9 variantes que también describen la situación de crisis y de restricciones. Con una cifra del $23,33 \%$ es el tercero del ranking de porcentajes (ver tabla 10)

Llevamos 70 años moviéndonos contigo. Es nuestra vocación y nuestra meta.

Pero en estos momentos, necesitamos que te detengas.

Parar ahora es pensar en los demás. Es seguir las recomendaciones. Es, por encima de todo, quedarse en casa. Per no te preocupes, seguimos estando contigo. Y cuando llegue el momento. Volveremos a movernos juntos.

(YouTube. Seat España, 2020)

Al contrario que Volkswagen, el spot con menos Ud. R. empleadas es Movistar de Telefónica, con tan solo 1 sobre un total de 20 palabras que han empleado para su copy, alcanzando un $5 \%$ quedando en el puesto 14 del ranking de porcentajes. Sin embargo, es El Corte Inglés, el anunciante que menor porcentaje consigue usando tan solo 2 palabras de la selección sobre 47 del total del texto publicitario quedándose muy por debajo de la media con un $4,26 \%$.

Pero si hay dos anunciantes que destacan por tener el mayor porcentaje de uso de esas variables en sus textos son Volkswagen y la Mutua Madrileña con un $27,78 \%$ y un $23,33 \%$ respectivamente. Volkswagen usa 5 registros en tan solo un copy de 18 palabras y La Mutua introduce 7 en su mensaje de 30. Sin duda difiere mucho del valor más alto que obtiene Coca Cola en su anuncio del 2019, que obtiene tan solo un 8,16\%. A esto se puede añadir la diferencia significativa del promedio total de porcentajes que hay entre el 3,39\% del 2019 frente a un 12,79\% del 2020. (Ver tablas 2 y 3) 
Sánchez Sandoval, R.

Análisis lexicométrico de los mensajes publicitarios de las grandes marcas en España ante la crisis del COVID

Respecto a las Ud. R. todo/s con 14, volver, con 13 inserciones, y seguir con 11 son las más usadas en los spots seleccionados del 2020. En el lado opuesto de la tabla se encuentran términos como venir, pandemia, nuevo, ir y COVID con tan solo un uso de 1 unidad entre los 15 anunciantes seleccionados para la muestra. (ver tabla 10)

Tabla 10. Frecuencia del uso de Ud. R. en los anuncios del 2020

\begin{tabular}{|c|l|c}
\hline \multicolumn{2}{|c|}{ UNIDADES DE REGISTRO } & 2020 \\
\hline 1 & TODO/S & 14 \\
\hline 2 & VOLVER & 13 \\
\hline 3 & SEGUIR & 11 \\
\hline 4 & CASA & 7 \\
\hline 5 & AHORA & 5 \\
\hline 6 & ESTO/S & 5 \\
\hline 7 & NUNCA & 5 \\
\hline 8 & PROTEGER/SE & 5 \\
\hline 9 & AYUDA/R & 4 \\
\hline 10 & CUIDAR/SE & 4 \\
\hline 11 & JUNTOS & 4 \\
\hline 12 & MOMENTOS & 3 \\
\hline 13 & QUEDAR/SE & 3 \\
\hline 14 & RESISTIR & 3 \\
\hline 15 & VIRUS & 3 \\
\hline 16 & COVID & 1 \\
\hline 17 & IR & 1 \\
\hline 18 & NUEVO & 1 \\
\hline 19 & PANDEMIA & 1 \\
\hline 20 & VENIR & 1 \\
\hline
\end{tabular}

Fuente: Elaboración propia

Respecto a los verbos que se han seleccionado, se puede afirmar que volver es el más usado durante el 2020, siendo utilizado un total de 13 veces por 7 anunciantes distintos. Usado como recurso para indicar el momento en que todo regrese a su estado normal dentro de un estilo de vida habitual como el que se tenía antes de la pandemia. Como podemos observar en el copy casi poético de L'Oreal de ese año:

Sí, hay belleza en volver, en volver a tu tienda habitual y encontrarte con esas personas que siempre tienen el consejo perfecto. El volverte a dar esos pequeños caprichos de belleza. Por eso tus marcas de belleza favoritas te ayudamos con un $30 \%$ de descuento para que, ahora que puedes cuidarte mejor, vuelvas a comprarles cuando más lo necesitan. Disfruta la belleza de volver.

(YouTube. L’Oreal Paris España. 2020)

Sin duda, con esta figura de repetición del verbo volver, aumenta la media del uso de este verbo, pero son 6 anunciantes más los que la usan con un significado similar, como en el spot de la Mutua Madrileña del mismo año que dice "Mientras nosotros cuidamos de tus cosas. Queremos que nos hagas una promesa. Que cuidarás de ti y de los tuyos. Todo volverá a la normalidad. Hasta entonces, quédate en casa. \#Estevirusloparamosunidos"

(YouTube. Mutua Madrileña. 2020) 
De entre los léxicos seleccionados, los que no se han usado en ningún spot del 2019 son; ahora, COVID, cuidar(se), momentos, pandemia, proteger (se) y resistir. Tiene su lógica ya que resultan palabras más apropiadas para haberse usado en las campañas del año 2020, sobre todo COVID, ya que es una palabra técnica sanitaria que no se conocía fuera de este sector hasta que no se llegó al estado de pandemia. Aun así, en el 2020 a penas se han usado; tan solo H\&S se atreve a pronunciar COVID en su copy "A todos los que nos sostienen con la cabeza alta. Y a los que les apoyan desde casa. Hombro con hombro. Estando unidos nada nos va a parar. Sigamos adelante. HES. Con la cabeza alta. Colabora con \#CRUZROJARESPONDE frente al COVID-19". Opel, también apela a la palabra pandemia en su redaccional, "... Volver a recorrer muchos kilómetros juntos. Ofreceros nuestra ayuda contra la pandemia."

Quizás, por tener esas connotaciones negativas, el resto de los anunciantes del corpus escogido no han querido usarla ya que la palabra está a todas horas presente en los medios de comunicación, apareciendo diariamente en las noticias. Las empresas, se entiende, que quieran dar mensajes positivos.

Llama la atención que en el 2019 los términos más usados sean venir, ir y nuevo, precisamente los menos empleados en el 2020, (ver tablas 6 y 10). Podría ser un indicativo de ese cambio de estrategia comunicativa que se plantea como objetivo principal de este estudio.

En la tabla 11 de anexos, se puede apreciar el cambio de dirección en cuanto a contenidos de los mensajes. En el 2019, 11 empresas dirigieron su comunicación hacia objetivos comerciales a excepción de Orange, Coca Cola y ONCE que usaron sus espacios publicitarios para mandar mensajes sociales, de imagen o corporativos.

Sin embargo, se ve un cambio de tendencia en esos 11 anunciantes en el 2020 virando su estrategia comunicativa con una doble intencionalidad: comercial y social. Se implican en el problema de la crisis, pero sin dejar de hacer un "guiño" a sus productos o servicios. Por el contrario, Coca Cola y ONCE, cambian ese mensaje corporativo de imagen por otro más social, dejando a un lado sus servicios y actividades para dar protagonismo al mensaje de compromiso con la sociedad.

\section{CONCLUSIONES}

Los datos extraídos reflejan varios resultados concluyentes, aunque partiendo de la base de que la muestra no es excesivamente amplia, sí es suficiente para realizar un análisis exploratorio para determinar la frecuencia del uso de ciertas palabras en los mensajes publicitarios del corpus de anuncios seleccionado.

Los datos cuantitativos extraídos, nos aportan datos cualitativos significativos, que no se pueden obviar por lo que se tendrán en cuenta como posibles datos concluyentes. Es evidente que, al extraer información de datos comparativos entre ambos años, se puede aportar conclusiones también comparativas que diferencian las acciones y actitudes de las empresas en un año respecto del otro. 
Análisis lexicométrico de los mensajes publicitarios de las grandes marcas en España ante la crisis del COVID

Se puede confirmar que en el 2020 el uso de las unidades de registro ha aumentado significativamente, de 2,40 palabras de media por anuncio en 2019 a 6,27 en 2020. Por lo tanto, si tenemos en cuenta los valores de los promedios respecto al total de las palabras de cada año, se puede concluir que los porcentajes para el 2019 y 2020 son de un $3,39 \%$ y un $12,79 \%$ respectivamente, lo que ratifica y mejora los datos significativamente más de 9 puntos porcentuales.

En el 2020, se puede apreciar una reducción de uso de la palabra, de 1063 que se usaron en 2019 a 735, una reducción de 328 unidades léxicas, un 31\% menos. Dato bastante significativo que puede tener ciertas connotaciones como que, en 2020, durante el comienzo de la situación de crisis sanitaria, el mensaje fue más directo, menos comercial, con menos perífrasis para adornar la comunicación de los productos.

En el 2020 se observa cómo la totalidad de la muestra ha incluido alguna palabra, dato, expresión que representa o identifica la situación de crisis sanitaria del momento, en mayor o menor medida. Lo que indica ese cambio estructural en su estrategia comunicativa virando de un mensaje comercial a uno más social. Aprovechan sus espacios publicitarios para mandar mensajes de apoyo, de ayuda e incluso de recuerdo de las recomendaciones sanitarias impuestas por el Gobierno. Marcas como La Mutua Madrileña o la ONCE en 2020 tienen mensajes de carácter absolutamente de apoyo y solidarios ante la situación actual.

Hay que destacar que Vodafone elabora una continuidad en la narrativa de su anuncio del 2019 adaptándolo a la situación del 2020. Mismos personajes, mismo insight pero con una intención diferente, sin dejar de mostrar sus servicios comerciales, adapta el resto del mensaje a una intención social.

Según la observación del significado de las variables elegidas, el desuso en el 2020 de palabras como ven o nuevo, indican también ese cambio de dirección del mensaje, invitaciones a probar un producto, comprarlo, ir a verlo, etc. se sustituyen por otras como resistid o juntos con unas connotaciones más de lucha, de resistencia, de apoyo para retornar a una situación normal, que ahora se hace tan difícil de conseguir. Un buen ejemplo es la frase apelativa de Volkswagen "Resistid amigos, resistid" o el de H\&S "Estando unidos nada nos va a parar. Sigamos adelante" o como dice Opel "Juntos somos más fuertes en las buenas y en las malas". Frases todas ellas que, como puede observarse, apelan a la situación de crisis del momento actual.

Por otra parte, también se podría afirmar que este año ha sido un proceso de aprendizaje durante el cual las marcas han querido acercarse al consumidor con mensajes más cercanos y empáticos, donde toman partido del problema que afecta a todos, personas, empresas, economía, etc. Eso lo refleja muy bien Seat en su anuncio del 25 de marzo, que publicó tan solo 10 días después de establecerse el estado de pandemia mundial:

Llevamos 70 años moviéndonos contigo. Es nuestra vocación y nuestra meta.

Pero en estos momentos, necesitamos que te detengas.

Vivat Academia. Revista de Comunicación. 2021, nº 154, 185-212 
Parar ahora es pensar en los demás. Es seguir las recomendaciones. Es, por encima de todo, quedarse en casa. Per no te preocupes, seguimos estando contigo. Y cuando llegue el momento. Volveremos a movernos juntos.

(YouTube. Seat España, 2020)

A todo lo anteriormente dicho, habría que sumar, aunque daría para otro estudio específico, que a estos textos los acompañan imágenes sacadas de momentos de confinamiento, de unión, de agradamiento y de apoyo. Esto, efectivamente, ayudaría a corroborar el objetivo principal de este estudio, que es indagar en la existencia de un cambio sustancial de estrategia comunicativa en los copies de estas marcas hacia un mensaje más social en detrimento de su estrategia comercial inicial. No obstante, a la luz de los resultados, y atendiendo únicamente al estudio y análisis lexicométrico propuesto, es posible afirmar que justo eso es lo que finalmente ha sucedido. Asimismo, cuando toda esta situación se aleje en el tiempo, otras investigaciones emprendidas bajo la perspectiva que aporta la toma de distancia con el fenómeno objeto de estudio, servirán para arrojar más luz sobre este momento inédito de nuestra historia y su relación con la emisión de nuevas estrategias de comunicación publicitarias dirigidas a solventar la difícil situación vivida.

\section{REFERENCIAS}

Amazon.es. (2020, 28 de mayo). ¿Qué estamos haciendo? (Video). YouTube. https://youtu.be/dhRrc68TwJ0

Anunciantes. (2020, 7 de octubre). Observatorio de la publicidad 2020. https://www.anunciantes.com/noticia/sector-publicitario-incrementa-55generacion-volumen-negocio/

Anuncios tv. Mutua madrileña. (2019, 5 de noviembre). Vamos Mútuate. (Video). YouTube. https://youtu.be/Ol28jLgUMyA

Caride, M. (2019). El concepto "crisis" en el mensaje publicitario. (Tesis de Facultad Ciencias de la Información del repositorio de la Universidad Complutense de Madrid) Google Scholar. https://eprints.ucm.es/id/eprint/58874/

Coca Cola Journey España. (2020, 17 de agosto) Volveremos para apreciar nuestros bares. (Video). YouTube. https://youtu.be/u5qxrDvqlzs

Coca- Cola. (2019, 10 de febrero). Es hora de juntarnos para comer. (Video). YouTube. https://youtu.be/obHoaKSwkis

Delgado, J. y Gutiérrez, J. (1995). Métodos y técnicas cualitativas de investigación en ciencias sociales. Síntesis. 
Sánchez Sandoval, R.

Análisis lexicométrico de los mensajes publicitarios de las grandes marcas en España ante la crisis del COVID

El Corte Inglés. (2019, 28 de junio) Ya están aquí \#LasRebajas más refrescantes del verano. (Video). YouTube. https://youtu.be/ioM4HTIL_Xc

El Corte Inglés. (2020, 18 de junio). 4 días de los grandes descuentos. (Video). YouTube. https://youtu.be/BTEtq0jrMAo

Expansión. El 52\% de las marcas detuvo su inversión publicitaria por el COVID-19 (2020, 13 de mayo). https://expansion.mx/mercadotecnia/2020/05/13/marcas-decidenretener-inversion-publicitaria-por-seis-meses

Fernández, M. A. y Fuentes, J. F. (2000). Análisis lexicométrico de El Socialista (1886-1912): un vocabulario de clase. Historia contemporánea. $\mathrm{N}^{0}$ 20. Págs. 225-246. Alianza Editorial. https:/ / dialnet.unirioja.es/servlet/articulo?codigo=150029

Fundación ONCE. (2019, 2 de diciembre) ¡La ilusión puede con todo! (Video). YouTube. https://youtu.be/9hNk8O2MjUs

H\&S España. (2019, 8 de febrero). Leyendas del mañana. (Video). YouTube. https://youtu.be/iP3ufUAaGJg

H\&S España. (2020, 15 de abril). Sigamos Adelante. (Video). YouTube. https://youtu.be/gq5sqRB5efA

Hernando Cuadrado, L. A. (s.f.). (2012) Análisis semiótico del mensaje publicitario. Universidad de Guadalajara. México. http:// biblioteca.udgvirtual.udg.mx/jspui/handle/123456789/3656

Hernando Cuadrado, L. A. (1994). Semiótica y modernidad: actas del V Congreso internacional de la Asociación Española de Semiótica. La Coruña. 1992. 2, 513-524. Dialnet. http://hdl.handle.net/2183/8661

Infoadex. NP Estudio Infoadex de la inversión publicitaria en España 2020. Consultado el 20 de noviembre de 2020. https://www.infoadex.es/home/

Krippendorff, K. (1990) Metodología de análisis de contenido. Teoría y práctica. Barcelona. Paidós. (Edición original inglesa en 1980. Sage. Newbury Park)

L'Oreal Paris España. (2020, 3 de junio). Disfruta la belleza de volver. (Video). YouTube. https://youtu.be/yPFQsCG1gaA

L'Oreal Paris España. 2019, 11 noviembre No hay barreras entre tu piel y tu maquillaje. (Video). YouTube. https://youtu.be/FOIe9jfsiaI

Línea Directa Aseguradora (2019, 25 de febrero). 6 meses gratis en tu seguro. (Video). YouTube. https://youtu.be/wHkb9WflM8k 
Sánchez Sandoval, R.

Análisis lexicométrico de los mensajes publicitarios de las grandes marcas en España ante la crisis del COVID

Línea Directa Aseguradora. (2020, 20 de abril). Seguro de Hogar con pago fraccionado. (Video). YouTube. https://youtu.be/9dz9t5xYAGQ

Lopez-Noguero, F. (2002): El análisis de contenido como método de investigación. XXI Revista de Educación. Universidad de Huelva. https:/ / dialnet.unirioja.es/servlet/articulo?codigo $=309707$

López, M. A. L., San José, C. R., Núñez-Cansado, M. (2020). El universo material del lujo en la filmografía de Pedro Almodóvar: entre moda y tradición. Valencia. Tirant lo Blanch.

Lugar Music. Volkswagen España. (2019, 2 de abril) “Felices los 3”. (Video). YouTube. https://youtu.be/BLOB96QuFVM

Ministerio de la Presidencia, Relaciones con las Cortes y Memoria Democrática (2020, 14 de marzo) Real Decreto 463/2020, de 14 de marzo, por el que se declara el estado de alarma para la gestión de la situación de crisis sanitaria ocasionada por el COVID-19. «BOE» núm. 67, de 14/03/2020. BOE-A-2020-3692. https:// boe.es/buscar/act.php?id=BOE-A-2020-3692

Movistar España. 2019, 27 de noviembre. Reinventa tu hogar con Movistar Home. (Video). YouTube. https://youtu.be/QEW_EdNOiLc

Movistar España. Cuando estamos conectados somos capaces de hacer cosas increíbles. (2020, 27 de marzo). (Video). YouTube. https://youtu.be/L0jAizXCohs

Mut Camacho, M. y Bernad Monferrer, M. E. (2012). El mensaje comprometido es otra publicidad. Vivat Academia, https://doi.org/10.15178/va.2011.117E.598-611

Mutua Madrileña. (2020, 20 de marzo). Cuida de ti y de los tuyos. (Video). YouTube. https://youtu.be/s2FnSIalY1k

Navarro, P. y Díaz, C. (1994): “Análisis de Contenido" en Delgado, J.M. y Gutiérrez, J.coordinadores- Métodos y técnicas cualitativas de investigación en ciencias sociales. Madrid. Síntesis Psicología. Pps.177-224.

Ojo Iberoamérica 2020. (2020, 2 de diciembre) El palmarés español: 64 premios. https://ipmark.com/ojo-iberoamerica-2020-el-palmares-espanol-64-premios/

ONCE. Grupo social ONCE. (2020, 20 de marzo) ¡La ilusión puede con todo! (Video). YouTube. https://youtu.be/nNkHTsAQv7o

Opel España. (2019, 15 de noviembre). Nuevo Opel Corsa. (Video). YouTube. https://youtu.be/s2vkZPGWJJ0 
Sánchez Sandoval, R.

Análisis lexicométrico de los mensajes publicitarios de las grandes marcas en España ante la crisis del COVID

Opel España. (2020, 16 de abril) Nuestro compromiso: seguir en marcha por ti. (Video). YouTube. https://youtu.be/JmYdtmYBlVM

Orange España. (2019, 25 de septiembre). Las princesas no comen. (Video). YouTube. https://youtu.be/WHoXAw5_gcw

Orange España. (2020, 20 de marzo). La tecnología no sustituye a los que más quieres. (Video). YouTube. https://youtu.be/H-NsFpGYjb0

Organización Mundial de la Salud. Consultado el 10 de enero de 2021. https://www.who.int/es/emergencies/diseases/novel-coronavirus-

2019/technical-guidance/naming-the-coronavirus-disease-(COVID-2019)-and-thevirus-that-causes-it

Pardo, C. E. (2000). Análisis de la Métrica en Aplicaciones de la Estadística Textual a la Tipología de Trayectorias. Revista Colombiana de Estadística, 23(1), 1-13. https://revistas.unal.edu.co/index.php/estad/article/view/28340

Pol, A. B. 2020. (2015) El futuro de las marcas (artículo). Cuaderno 53 Centro de Estudios en Diseño y Comunicación. pp 105-121. Universidad de Palermo. DOI: https://doi.org/10.18682/cdc.vi53. https://fido.palermo.edu/servicios_dyc/publicacionesdc/cuadernos/detalle_arti culo.php?id_libro $=525 \&$ id_articulo $=10843$

Real Academia Española. (2020). Diccionario de la lengua española (edición de tricentenario). https://dle.rae.es/

Reason Why. Los anuncios que nos está dejando el confinamiento (2020, 3 de abril). https://www.reasonwhy.es/actualidad/anuncios-marcas-confinamientocoronavirus

Rivas. C. (2020, 23 de octubre). La Inversión Publicitaria cae un -22,2\% en los nueve primeros meses de 2020. Infoadex. https://www.Infoadex.es/home/inversionpublicitaria-cae-22-septiembre-2020

Romero-Pérez, I., Alarcón-Vásquez, Y. y García-Jiménez, R. (2018). Lexicometría: enfoque aplicado a la redefinición de conceptos e identificación de unidades temáticas. Biblios, (71), 68-80. https://dx.doi.org/10.5195/biblios.2018.466

Seat España. (2019, 10 de noviembre). Nuevo Seat Terraco. Sigue Sumando. (Video). YouTube. https://youtu.be/qjGKRbFgXMU

Seat España. (2020, 25 de marzo). Llevamos años moviéndonos juntos. (Video). YouTube. https://youtu.be/iN-HeZ-sBAg 
Sánchez Sandoval, R.

Análisis lexicométrico de los mensajes publicitarios de las grandes marcas en España ante la crisis del COVID

Securitas Direct España. (2020, 23 de abril). Protegemos personas \#AhoraYSiempre. https://youtu.be/IiWAXh_IXWk

Securitas Direct. (2019, 5 de noviembre). Tu alarma para el hogar, tu negocio y las personas. (Video). YouTube. https://youtu.be/eg_K_Ap-xvU

Spots illustrated. Amazon echo. (2019, 25 de junio). Mi gran noche. (Video). YouTube. https://youtu.be/E-f6O3IFM3Y

Terrazas, W. (2016) Análisis lexicométrico aplicado al estudio de las concepciones de aprendizaje. Educ. rev. No 61, p 241-255. https://doi.org/10.1590/0104-4060.44222

Tomba, C., Muñoz, C. y Allisiardi, A. (2020). The social responsibility of advertising: the role of public property campaigns. [La responsabilidad social de la publicidad: el rol de las campañas de bien público]. Vivat Academia. Revista de Comunicación, 150, 103-129. doi: http://doi.org/10.15178/va.2020.150.103-129

Vázquez-Cano, E., Mengual-Andrés, S y Roig-Villa, R. (2015) Análisis lexicométrico de la especificidad de la escritura digital del adolescente en WhatsApp. Revista de Lingüística Teórica y Aplicada. Repositorio Universidad de Alicante, 53(1): 83-105. http://rua.ua.es/dspace/handle/10045/48306

Vodafone España. (2019, 19 de diciembre). ¿Pasamos más tiempo con el móvil que con nuestros seres queridos? (Video). YouTube. https://youtu.be/kMAn7CjEhHU

Vodafone España. (2020, 18 de marzo). Protejámoslos, protegiéndonos todos. (Video). YouTube. https://youtu.be/ANHJzXCY55Y

Volkswagen España. (2020, 2 de abril). ¡Te mereces un fin de semana con la gama California! (Video). YouTube. https://youtu.be/lTynEKEcVWk

\section{AUTOR:}

\section{Raquel Sánchez Sandoval}

Licenciada en Publicidad y Relaciones Públicas, Universidad Complutense de Madrid. Profesora asociada del Dpto. Historia Moderna, Contemporánea y de América. Periodismo. Comunicación Audiovisual y Publicidad en la Universidad de Valladolid en el Campus María Zambrano de Segovia (2000). Ha impartido asignaturas como: Teoría de la Imagen, Creatividad Online, Gestión Comercial de Empresas Multimedia, Gestión de Marca, Comunicación de Crisis, Publicidad Interactiva y Lenguaje Publicitario.

Orcid ID: https:/ / orcid.org/0000-0002-2502-0855 
Sánchez Sandoval, R.

Análisis lexicométrico de los mensajes publicitarios de las grandes marcas en España ante la crisis del COVID

\section{ANEXOS:}

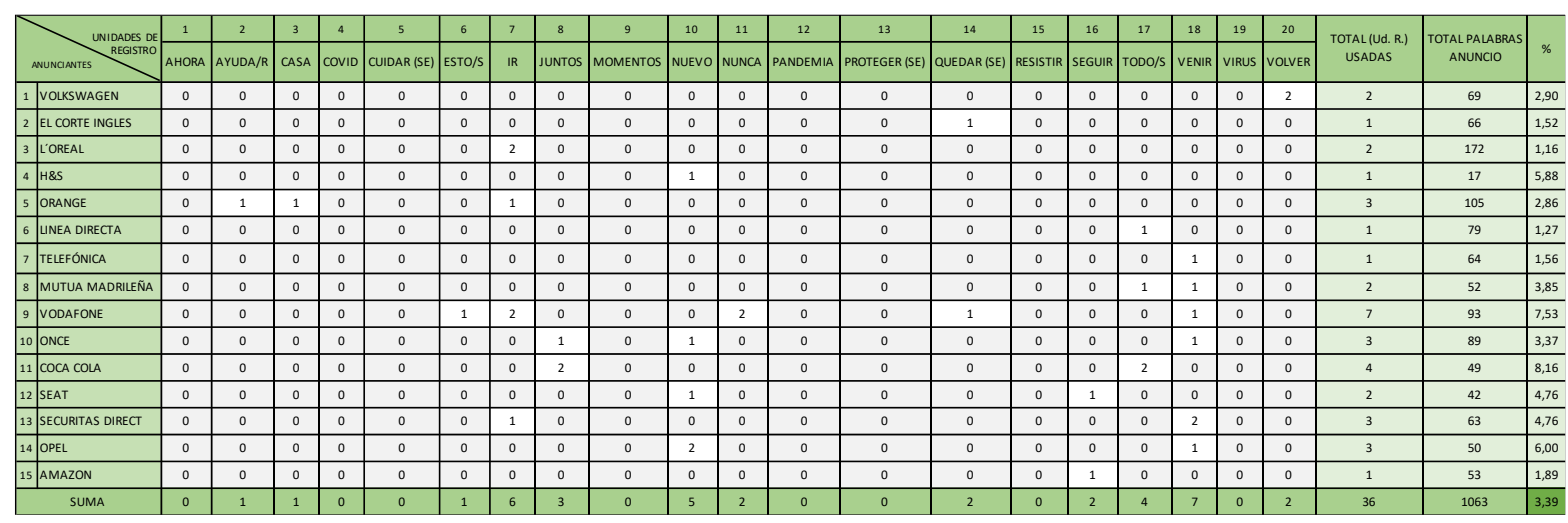

Tabla 2. Uso de variables en el corpus de anuncios en el año 2019

Fuente. Elaboración propia

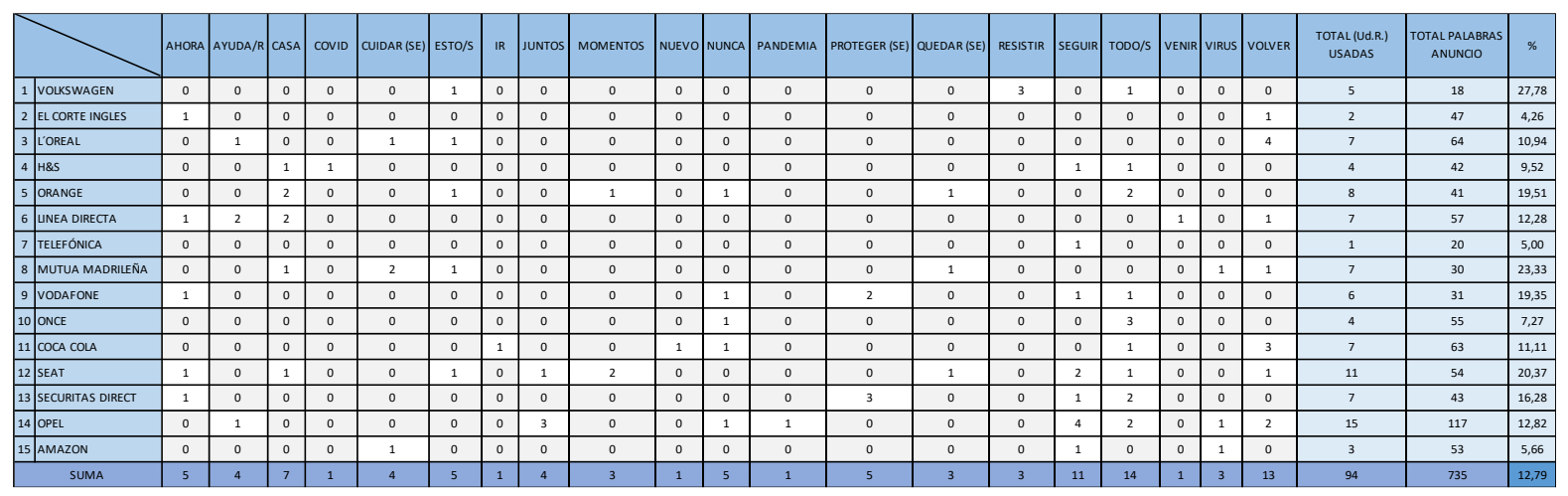

Tabla 3. Uso de variables en el corpus de anuncios en el año 2020

Fuente. Elaboración propia

Vivat Academia. Revista de Comunicación. 2021, nº 154, 185-212 
Sánchez Sandoval, R.

Análisis lexicométrico de los mensajes publicitarios de las grandes marcas en España ante la crisis del COVID

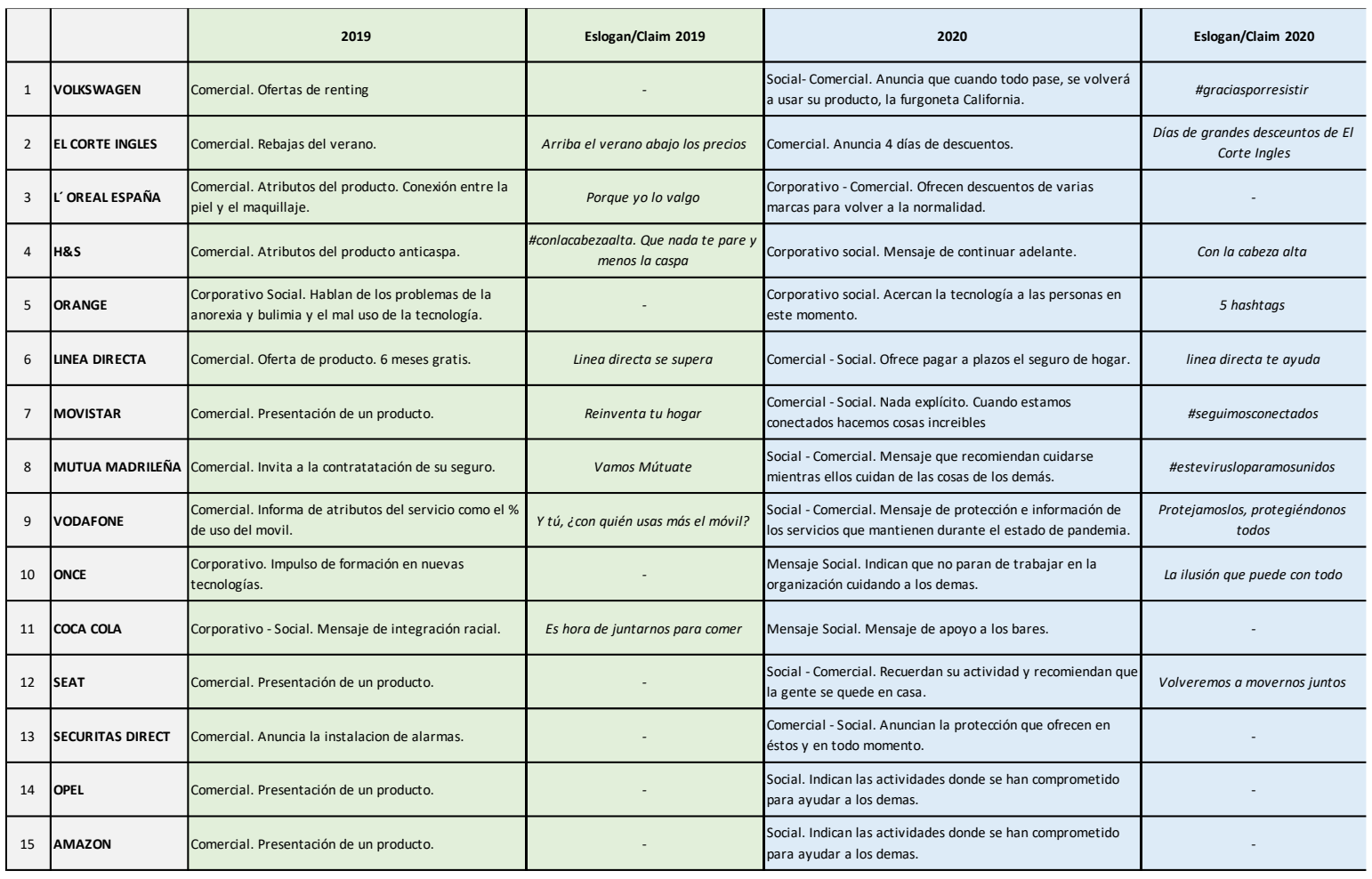

Tabla 11. Resumen comparativo de contenidos del total del corpus de anuncios. Fuente. Elaboración propia 